\title{
R\&D ERL: High Power RF Systems
}

\author{
A. Zaltsman
}

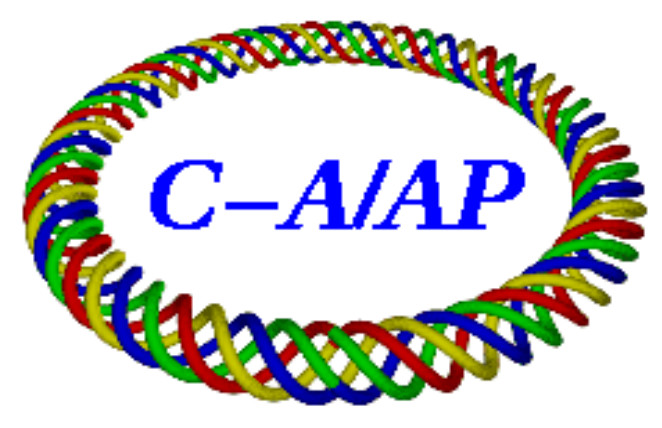

\section{Collider-Accelerator Department Brookhaven National Laboratory \\ Upton, NY 11973}

Notice: This document has been authorized by employees of Brookhaven Science Associates, LLC under Contract No. DE-AC02-98CH10886 with the U.S. Department of Energy. The United States Government retains a nonexclusive, paid-up, irrevocable, world-wide license to publish or reproduce the published form of this document, or allow others to do so, for United States Government purposes. 


\title{
R\&D ERL - High Power RF Systems
}

\begin{abstract}
Alex Zaltsman
ABSTRACT

The Energy Recovery Linac (ERL) project, now under construction at Brookhaven National Laboratory, requires two high power RF systems. The first RF system is for the $703.75 \mathrm{MHz}$ superconducting electron gun. The RF power from this system is used to drive nearly half an Ampere of beam current to $2.5 \mathrm{MeV}$. There is no provision to recover any of this energy so the minimum amplifier power is $1 \mathrm{MW}$. It consists of $1 \mathrm{MW}$ CW klystron, transmitter and power supplies, $1 \mathrm{MW}$ circulator, $1 \mathrm{MW}$ dummy load and a two-way power splitter. The second RF system is for the $703.75 \mathrm{MHz}$ superconducting cavity. The system accelerates the beam to $54.7 \mathrm{MeV}$ and recovers this energy. It will provide up to $50 \mathrm{~kW}$ of CW RF power to the cavity. It consists of $50 \mathrm{~kW}$ transmitter, circulator, and dummy load. This paper describes the two high power RF systems and presents the test data for both.
\end{abstract}

\section{MW system}

There are several main equipment groups in this system.

\section{$\underline{\text { Klystron }}$}

- Description - This tube, manufactured by CPI, is rated to produce $1.0 \mathrm{MW}$ $\mathrm{CW}$ at $703.75 \mathrm{MHz}$. This tube is similar to one produced by CPI for LANL, but the BNL tube does not have a modulating anode. The output of the tube is WR1500.

- $\quad$ Electrical Characteristics The collector is grounded, and $-92 \mathrm{kV}$ at $-17.1 \mathrm{~A}$ will produce $1 \mathrm{MW}$ in our tube.


While the maximum drive specified for $1 \mathrm{MW}$ is $100 \mathrm{~W}$ (40dB gain), this tube only requires $15.2 \mathrm{~W}$ to get full power. 
Other tube electrical requirements include the cathode heater, two solenoid circuits, and two 8 l/s vac-ion pumps. These are all controlled and monitored by the transmitter.

- Cooling - There are three water cooling loops, the collector requires $380 \mathrm{gpm}$, and is not temperature controlled. The two body loops are each about 7gpm, and are temperature controlled.

There are two inlets for forced air cooling of the output window, fed from one 100 CFM blower in the transmitter. The exhaust heat in this air plus the heat put into the air by the air cooled solenoids and other heat sources, must be removed from the radiation enclosure.

- Installation Issues - The collector end of the klystron has some lead shielding, but addition external shielding is required. A previous installation at LANL use a "lead garage" which was a lead lined enclosure where access to the klystron was by doors or rolling the garage away from the tube. In our installation, a steel room was used, and access was through full size doors.

- Development Issues - Even though this was similar to a tube manufactured by CPI previously, the output window cracked during the first acceptance test. There was a re-design of that area, and the tube performed flawlessly during the second acceptance test, even at $110 \%$ power.

- Purchase Costs - The order for this tube was placed in the summer of 2004, and the cost was $\$ 610 \mathrm{k}$.

\section{$\underline{\text { Transmitter }}$}

- Description - The largest part of this transmitter manufactured by Continental Electronics Corporation is the power supply. Its basic design is to stack 96 isolated IGBT gated power supplies in series. Because the IGBTs permit a fast shut down mode, a crow bar is not required to limit the energy in an arc to 40 Joules.

The transmitter also contains the support equipment for the klystron, including the filament power supply, two solenoid power supplies, two vac-ion pump controllers, several cooling water monitoring circuits, two air blowers -




one for the klystron window and one for a window in the ring, a RF amplifier, and a PLC to keep track of everything, including interlocks and monitoring of directional couplers in the system.

- Electrical Characteristics

o AC Input: $4160 \mathrm{VAC}$ (chosen to match the previous design)

o DC Output: $-100 \mathrm{kV}$ at $-21 \mathrm{~A}$

o Filaments: $30 \mathrm{Vrms}$ at 30 Arms, isolated to operate at $-100 \mathrm{kV}$.

o Solenoid PS: $30 \mathrm{~A}$ at $30 \mathrm{~V}$ and $30 \mathrm{~A}$ at $300 \mathrm{~V}$

o Vac-Ion Controllers: For 8 l/s pumps.

o Water circuits: Three at 400 gpm max (collector, RF load, beam dump), Four at 35 gpm max (body, output cavity, circulator, spare).

o Cooling Air: Two $100 \mathrm{cfm}$, filtered air

o RF Amplifier: $200 \mathrm{~W}$ max output, $52 \mathrm{~dB}$ gain

- Cooling - The unit is very efficient, as the IGBTs are switched at maximum rate of about $400 \mathrm{~Hz}$. This low frequency is consistent with a high ripple frequency as timing techniques result in a fundamental ripple frequency of almost $40 \mathrm{kHz}$.

The unit is entirely air cooled.

- Installation Issues

o Space - The transmitter is physically large, and requires a lot of interconnection between its elements. The installation took about a month.

o Safety - Appropriate safeguards must be put in place for personnel safety.

o Secondary Oil Containment - The high voltage tanks hold about 800 gallons of Envirotemp FR3, although this could be a little less in a new design.

- Development Issues - This system had many problems related to poor quality control by the manufacturer. This would not be our recommended vendor for future systems.

- Purchase Cost - The order for this transmitter was placed in the summer of 2004, and the cost was $\$ 2,225 \mathrm{k}$.

$\underline{\text { Water Load }}$

- Description - This water cooled dummy load, manufactured by CML Corp, is rated for $1.3 \mathrm{MW}$ of continuous power. It has a WR1500 waveguide input, a

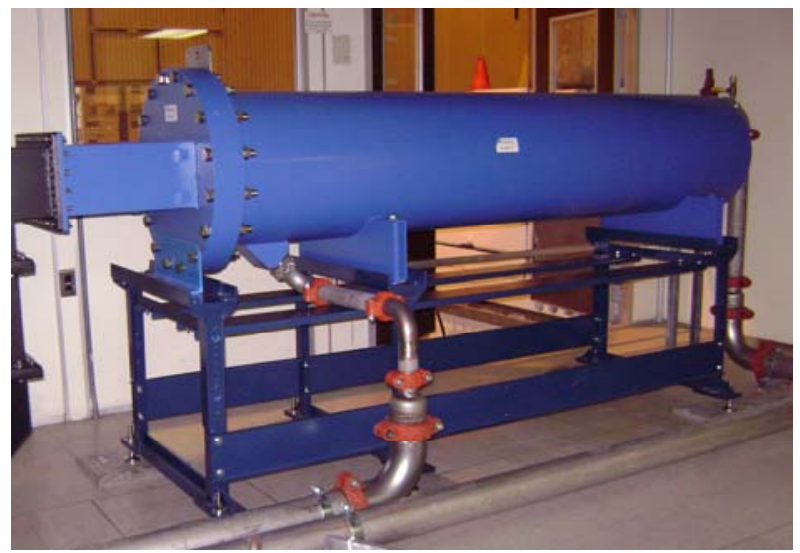


ceramic window, and a stand with six point leveling.

- Electrical Characteristics

o Continuous Power: 1.3 MW

o Center Frequency: $703.75 \mathrm{MHz}$

o VSWR: $1.05: 1$ at $\pm 2 \mathrm{MHz}, 1.2: 1$ at $\pm 20 \mathrm{MHz}$

- Cooling - 200 gpm

- Installation Issues - Metal plates were put under each leveling foot to distribute the weight of the water load when filled with water.

- Development Issues - We originally bought a water load with a Rexolite coupling window from an experienced waveguide manufacturer. This did not work as we melted two units in the $250 \mathrm{~kW}$ to $500 \mathrm{~kW}$ range. We then proceeded with the present unit with a ceramic window. While we have not tested this unit yet, others manufactured by CML have been shown to work well at high power.

While CML enjoys a strong reputation for quality, they enjoy an equally strong reputation for delivering items very late. I would recommend this company as a source, but I would order it early.

- Purchase Costs - The order for this load was placed in the summer of 2006, and the cost was $\$ 31.8 \mathrm{k}$.

\section{$\underline{\text { Circulator }}$}

- Description - This water cooled circulator is manufactured by AFT Microwave. In addition to the main unit shown here, there is a $3 \mathrm{U}$ rack mounted temperature controller unit. It is rated 1 MW into any port.

- Electrical Characteristics

o Center Frequency: $703.75 \mathrm{MHz}$

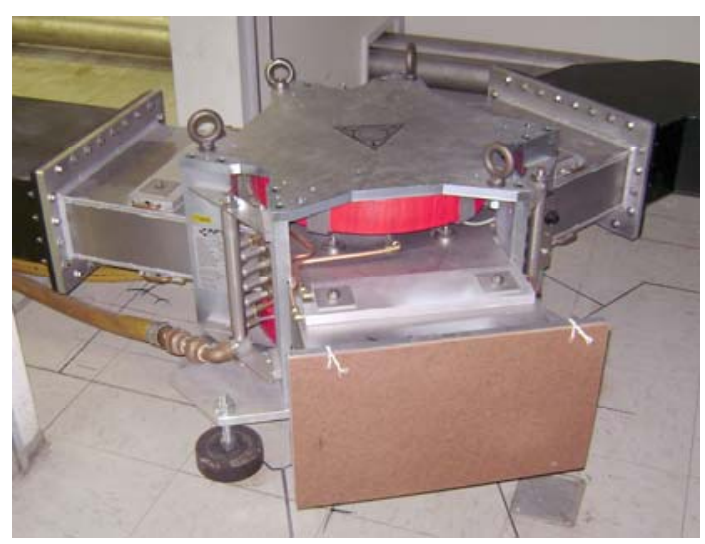

o Bandwidth: $\pm 17 \mathrm{MHz}$

o At Center Frequency:

- Insertion Loss: $<0.05 \mathrm{~dB}$, typ. $0.03 \mathrm{~dB}$

- Isolation: $>30 \mathrm{~dB}$

- VSWR: < 1.06

o In Bandwidth:

- Insertion Loss: $<0.1 \mathrm{~dB}$

- Isolation: $>20 \mathrm{~dB}$ 
- VSWR: $<1.20$

- Cooling - This unit requires about 4.5 gpm of de-ionized water. We supply this from a chiller to regulate the temperature.

- Installation Issues - The water from the chiller in this circuit is also monitored by the transmitter. Cabling is installed to remotely locate the temperature compensation unit.

- Development Issues - None.

- Purchase Costs - The order for this circulator was placed in the summer of 2006, and the cost was $\$ 165.4 \mathrm{k}$.

\section{Other Topics}

- In a similar installation at LANL, there was concern about reflected power of the harmonics of the klystron. These harmonics are $30 \mathrm{~dB}$ down, but at $1 \mathrm{MW}$ output, that's still a kW of energy. The tube manufacturer did not think this was necessary, and the VSWR of the harmonic filter reflected power at the fundamental. We didn't put one in.

- At the start of operation, an x-ray and RF safety survey is required. Additional $\mathrm{x}$-ray and RF monitoring is only done after construction changes. LANL chose to keep RF monitoring in place. 
Equipment Layout

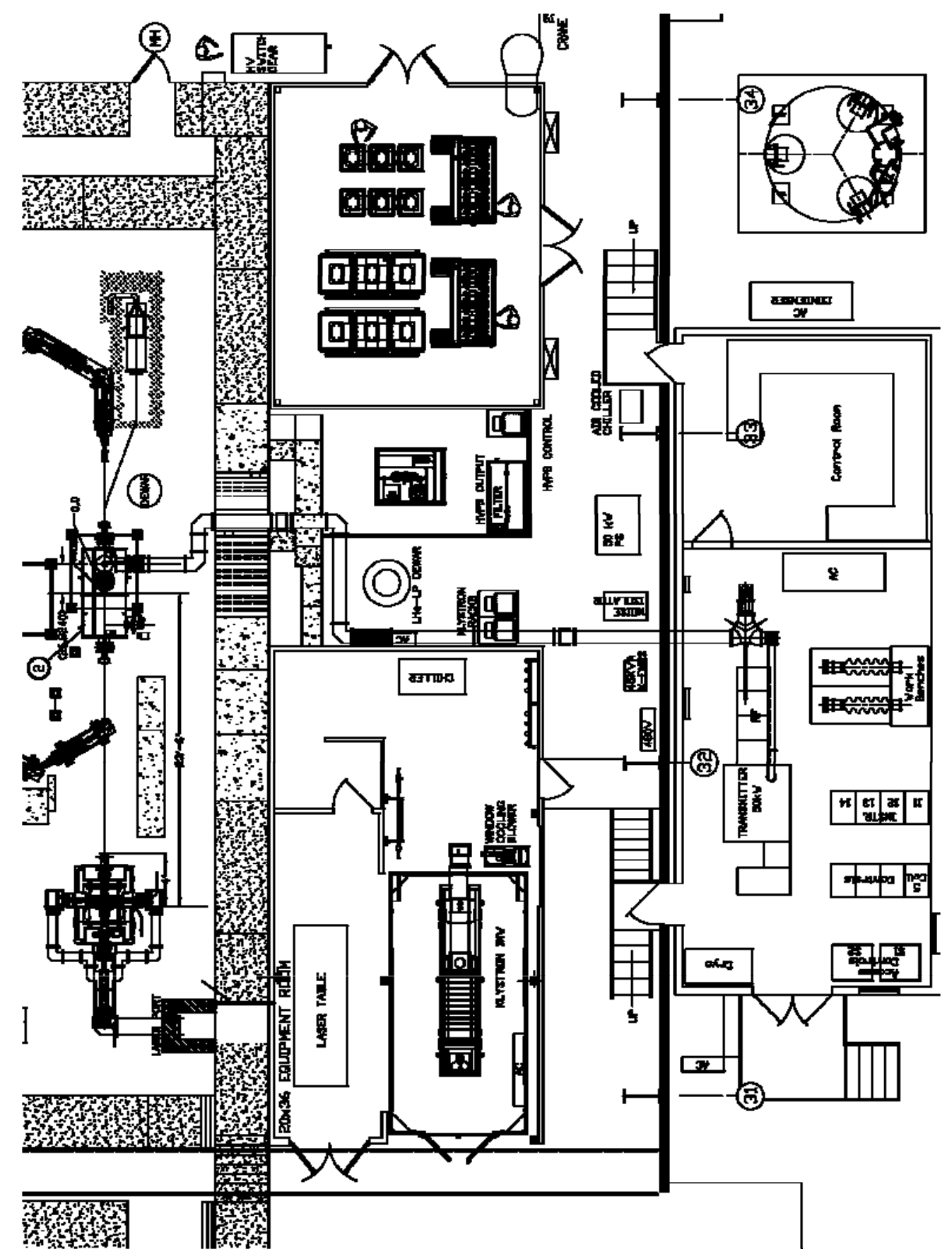




\section{0 kW system}

The 5 cell, $703.75 \mathrm{MHz}$ accelerating cavity has been tested at BNL to greater then 20 $\mathrm{MV} / \mathrm{m}$. Power necessary for conditioning and operation of it is 10 to $15 \mathrm{~kW}$. Because the frequency of it lays in the Digital TV band, the decision was made to utilize a standard, of the shelf TV transmitter. This gave us a good price and reliability as well as increase of power: the price difference between $20 \mathrm{~kW}$ and $50 \mathrm{~kW}$ system was less then $20 \%$ of the total cost.

\section{Scientific / Industrial IOT Amplifier System}



The Thomson SIIA Scientific and Industrial IOT Amplifier family is adapted from the highly successful, field-proven IOX and DCX family of high power IOT UHF television broadcast transmitter line. This line of equipment has been a world standard in the television broadcast industry. 
Inductive Output Tube (IOT) utilized in the amplifier is the industry standard for its high efficiency (over 50\%). It also provides a gain of 22 to $23 \mathrm{~dB}$ with remarkably low phase shift at wide range of output power.

To isolate and protect transmitter from very high VSWR we have installed a 50 $\mathrm{kW}$ circulator. Manufactured by AFT corporation it performed very well.

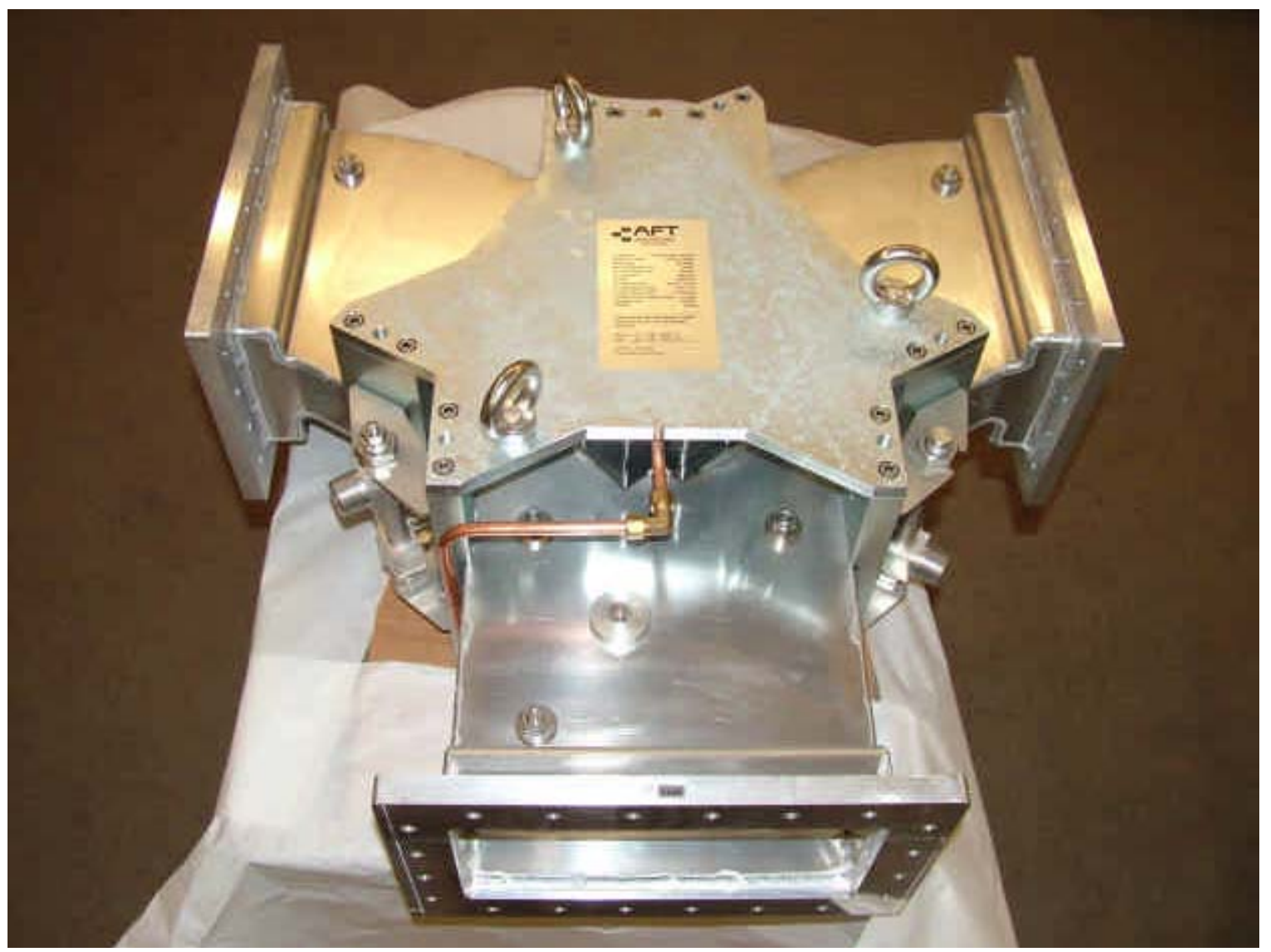

- Electrical Characteristics

o Center Frequency: $703.75 \mathrm{MHz}$

o Bandwidth: $\pm 2 \mathrm{MHz}$

o At Center Frequency:

- Insertion Loss: $<0.15 \mathrm{~dB}$, typ. $0.03 \mathrm{~dB}$

- Isolation: $>26 \mathrm{~dB}$

- VSWR: $<1.06$

o In Bandwidth:

- Insertion Loss: $<0.15 \mathrm{~dB}$

- Isolation: $>26 \mathrm{~dB}$ 
- Cooling - This unit requires about 4.5 GPM of de-ionized water. We supply this from a chiller to regulate the temperature. 